\title{
Home Security System Design and Implementation
}

\author{
Mohamed Hassan Ali Mohamed ${ }^{1}$, Dalia Mahmoud ${ }^{2}$ \\ ${ }^{1}$ Alneelain University, College of Graduates Studies, MSC in Control System Engineering, Khartoum, Sudan \\ 2Assistan professor, Control Engineering Department, Alneelain University, Khartoum, Sudan
}

\begin{abstract}
The idea of this project depends on the microcontroller to process the input data and gives the output signals. The home security system will be warning in the event of gas leaks, it's not allowed to open the doors or windows only if have the correct password in the event of typing wrong password, the siren will run.
\end{abstract}

Keywords: microcontroller, LCD, LPG, a siren, a keypad, password, Steeper motor drive, security system

\section{Introduction}

House security system it consists of four parts. Part one is IR transmitter, parts two is the receiver sensor, it works to protect the house from intruders at night and when there is no one at home. If the Infrared cut that indicates there are a thief or a persona non grata in the house, leading to running a siren. Part three is Liquid Petroleum Gas sensors which used in the kitchen or gas depots or places where is a gas warning the presence of leaking gas, the siren is running also when LPG sensor detected the gas Leak. Part four of security system is to open or close the doors or windows by password from keypad if the password is correct that means open or close the doors or windows and also display a message ,door/windows open/close ${ }^{\text {ee }}$ on the $\mathrm{LCD}$, if the password is error that means running the siren and display a message ,wrong password ${ }^{\text {ee }}$ on the LCD [1].

Of the most important things in our lives is security. All people would like to live a secure life. Control the entry and exit doors represent the first objectives of Security. A control system in the gates is a control system allows certain people to enter and prevents other people. The use of a microcontroller of the type PIC 16F177A so as to control the input signals and processed and give output signals based on the program saved in the memory. The user can change the old password from time to time because it was stored in the EPROM memory. The user can change the password for a keypad. If the password entered equal to the old password that is stored in the memory, the door or window will be open. And this is done via a microcontroller. Where the microcontroller sends the output signal to run the motor. [1].

Security an important topic since ancient times without security there cannot be stability or development in any areas. So was this project designs for homes, factories, hospitals etc... [2].

The project succeeded in the use of development that has occurred in electronic equipment components and microcontrollers type PIC 16F177A. Have also been using the latest sensors.

There are many types of security systems and this project is characterized by high efficiency and low cost. The planning, flow process, design and software and implementation the system was done successfully [3].

\section{Problem Statement}

The main idea of this project is to design and implement an integrated security system that allows specific people to enter via a password. The siren will be running when a case of entry of unauthorized person entering or there is a gas leak, and The Code was written by $\mathrm{C}$ language.

Using some of the electronic pieces components available, and to take advantage of after-sales service. We have thus maintained a safe environment free from theft and loss of property, crimes etc.

\section{Objectives}

The primary objectives of this paper are to design a home security system; using the microcontroller PIC16F177A.and programmed it using C language.

\section{Methodology}

In this paper, the microcontroller will be used to control the signal input from IR Transmitter, IR Receiver, LPG Gas sensor, and Keypad gives an output signal to LCD, Buzzer/siren, and Motor Driver to run the stepper motor according to the program in the microcontroller. The flow chart is shown in Figure 1 gives the details of the process. 


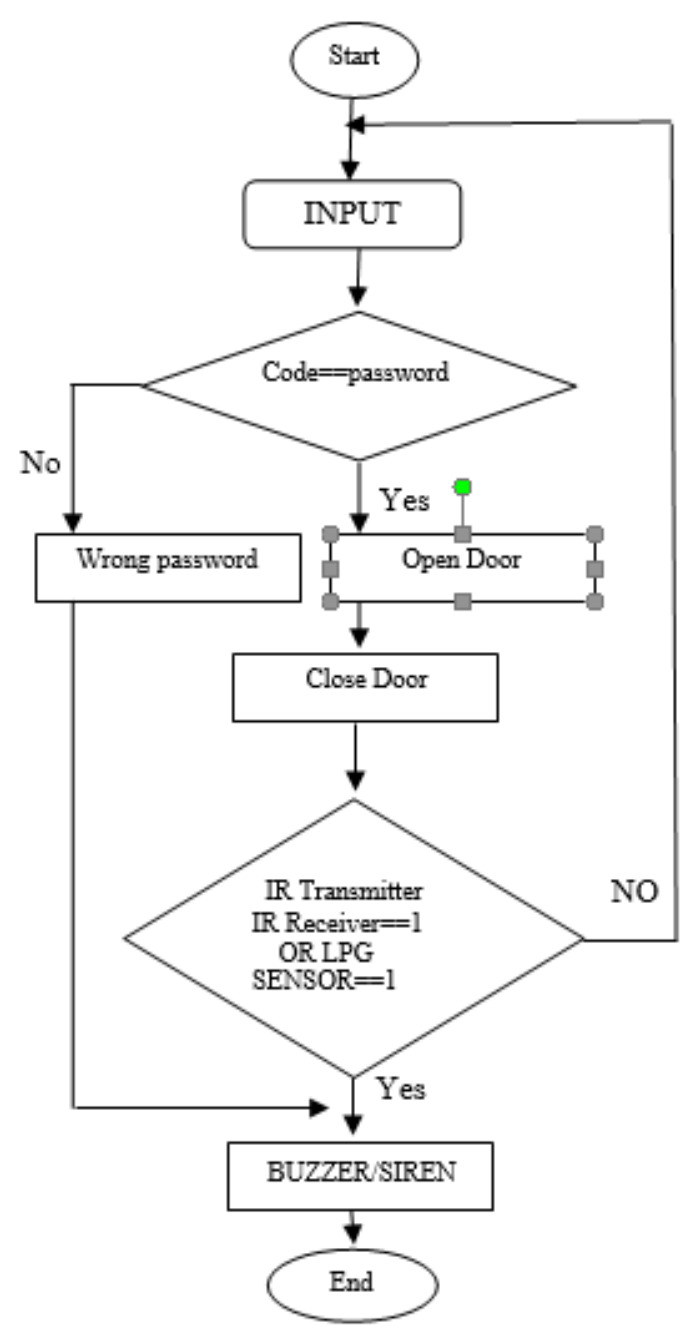

Figure 1: The flowchart of the Home security system

\subsection{Flowchart Description}

After the model start the LCD display start massage after 2000 MS. User enters the password from the keypad, where was saved in the memory. If the password is „YES that means to send the signal from microcontroller to stepper motor drive to rotate Steeper motor clockwise to opening the door or window and display "door/window open" in LCD. After 2000 MS send the signal to motor drive to rotate the Steeper motor anti- clockwise to close the door and print "door/window close” on LCD. If „NO ,that means print "wrong password" and send the signal from microcontroller to buzzer.

If the IR Transmitter equals the IR Receiver or LPG sensor equal one that means „YES ${ }^{\text {ee }}$ and the microcontroller will send the signal to Siren/Buzzer. If the result equal „,NO that means back to check input again.

\subsection{Block Diagram}

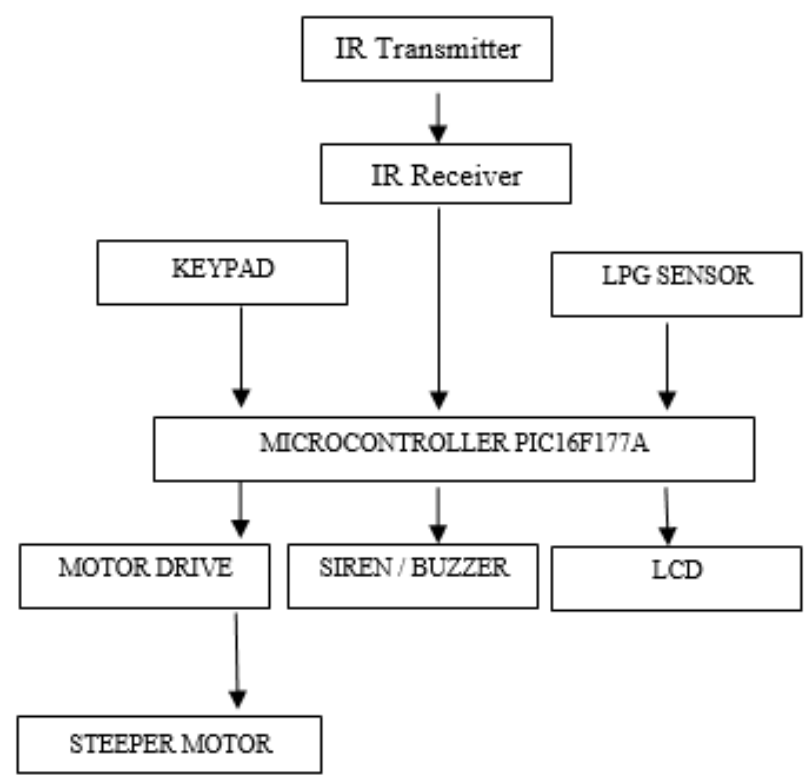

Figure 2: The Block Diagram

As shown in the figure above the system contains infrared sensor "IR Transmitter and IR Receiver" sender and receiver. As is known cannot see infrared, so it used in this project. The Keypad is used to enter a password to open and close the door, which is about the panel type $4 * 4$.

Liquid Petroleum Gas sensors it senses the presence of gas and sends a signal processor.

\section{The Microcontroller PIC16F177A}

The microcontroller used the type of the PIC family 16F177A it process the input signal according to the program saved in the memory and give output signal according to that program.

Output signals can open the door/window or gives an alarm or run siren and display a message on the LCD depending on the program and input signal.

The house security system project can be used in the different places, such as markets, banks, homes, hospitals etc. [1]

\subsection{Simulation \& Results}

This project was based on two parts:

The first part is the hardware, and the second part is the software. Section programming was implemented via micro $\mathrm{C}$ program and the program writing by $\mathrm{C}$ language. 


\section{International Journal of Science and Research (IJSR) \\ ISSN (Online): 2319-7064 \\ Index Copernicus Value (2013): 6.14 | Impact Factor (2014): 5.611}

Circuits \& Simulation Diagram of the project.

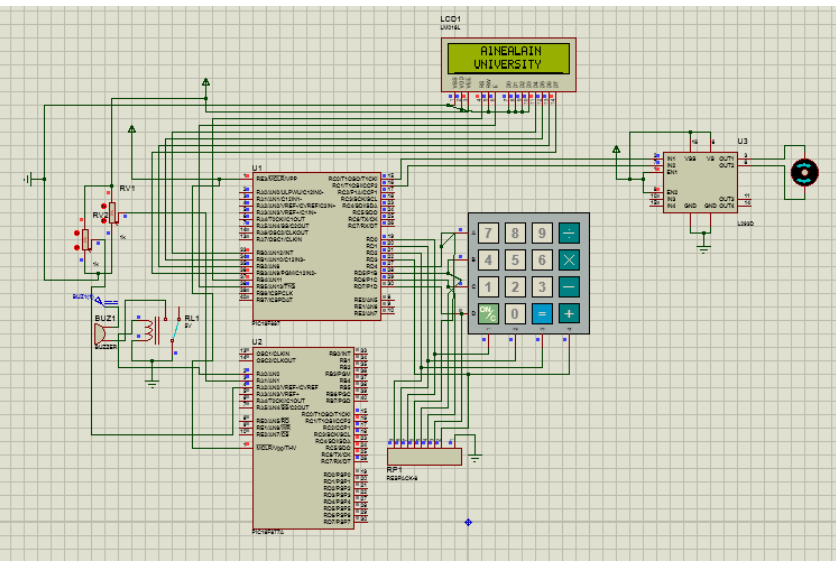

Figure 3: Shown circuit of home security system. Consist of two microcontroller PIC 16F177A.

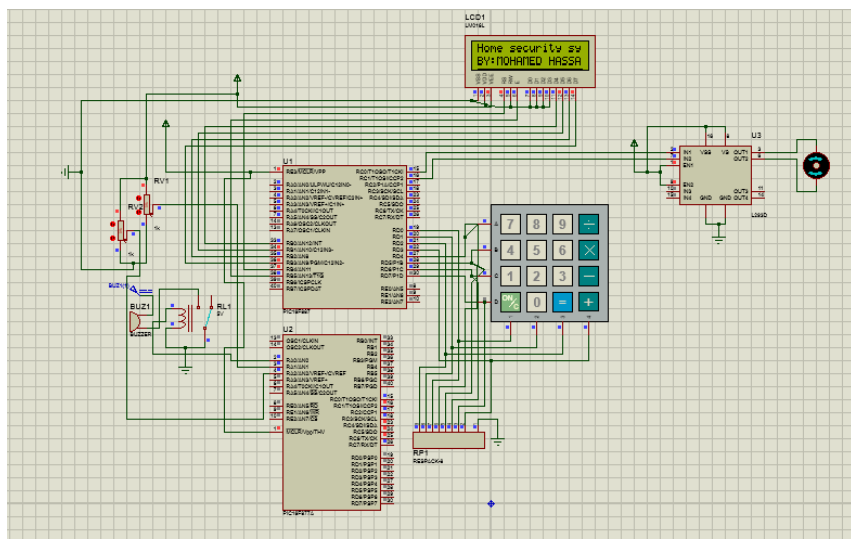

Figure 4: Shown the start operation system on LCD display

The LCD, keypad and motor drive was connected to the First microcontroller. The LPG sensor, IR transmitter, and IR receiver were connected to Second microcontroller.

The Buzzer / siren was connected to both microcontrollers.

After the system start, the user can enter the master code, to save the new password or change the old password. That shown in the next figures.

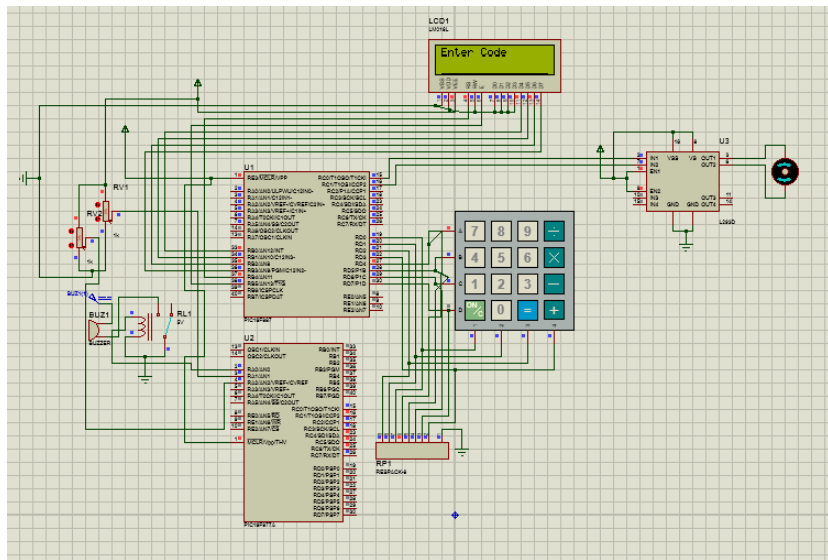

Figure 5: Shown re-enters the master code display on LCD.

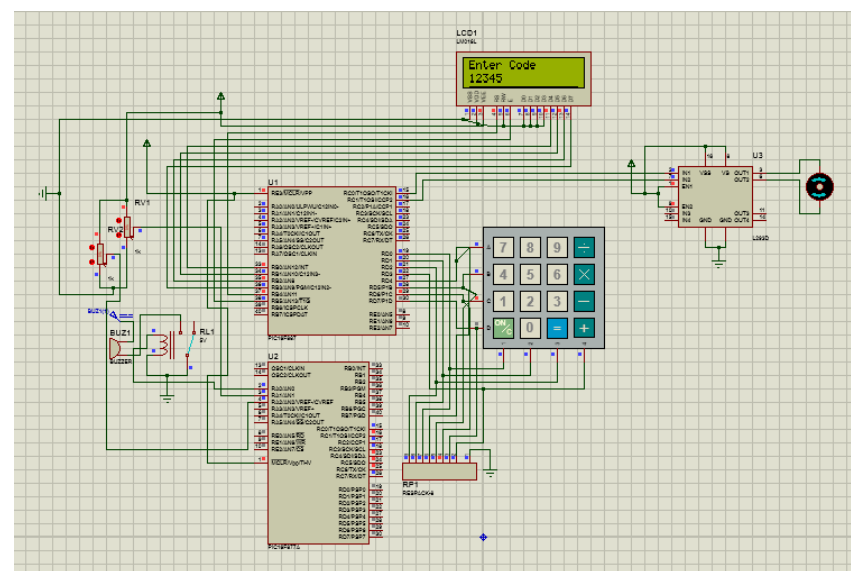

Figure 6: Shown the master code on LCD display

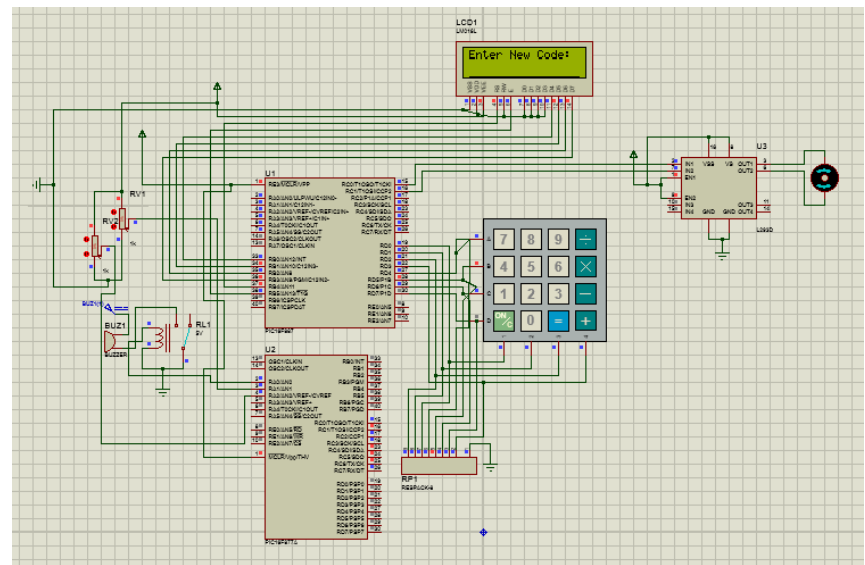

Figure 7: Shown pre-enter new code on LCD.

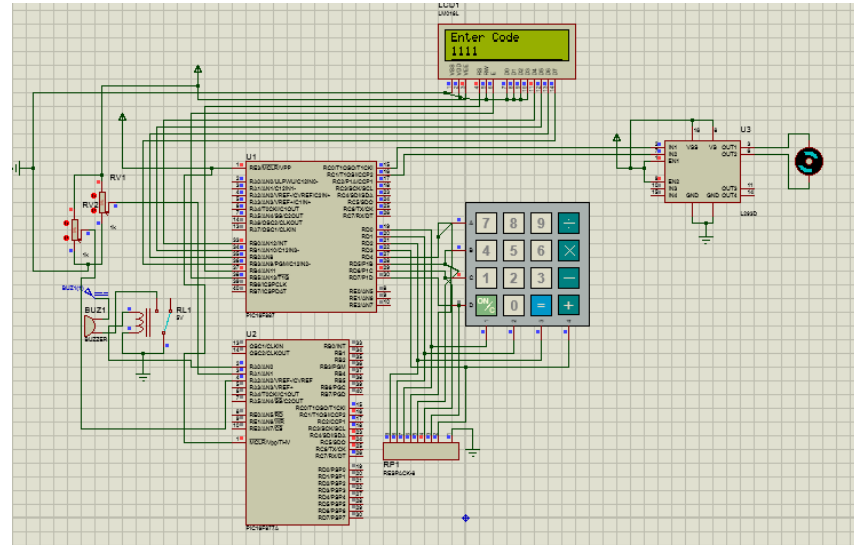

Figure 8: Shown new code on LCD.

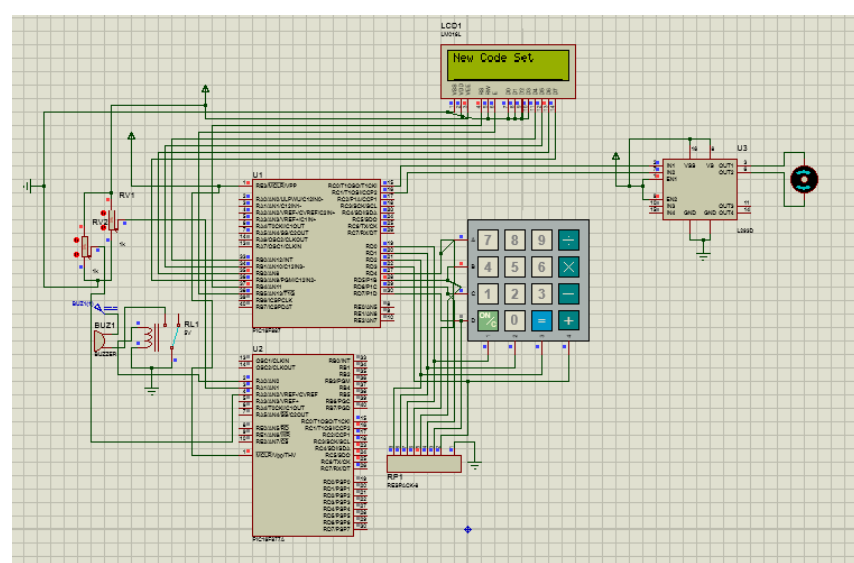

Figure 9: Shown new code set on LCD 
International Journal of Science and Research (IJSR)

ISSN (Online): 2319-7064

Index Copernicus Value (2013): 6.14 | Impact Factor (2014): 5.611

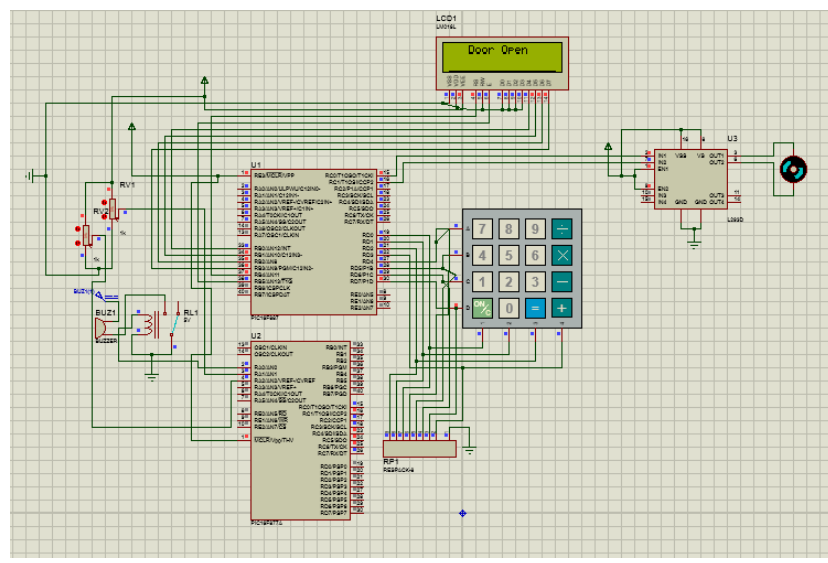

Figure 10: Shown door open on LCD.

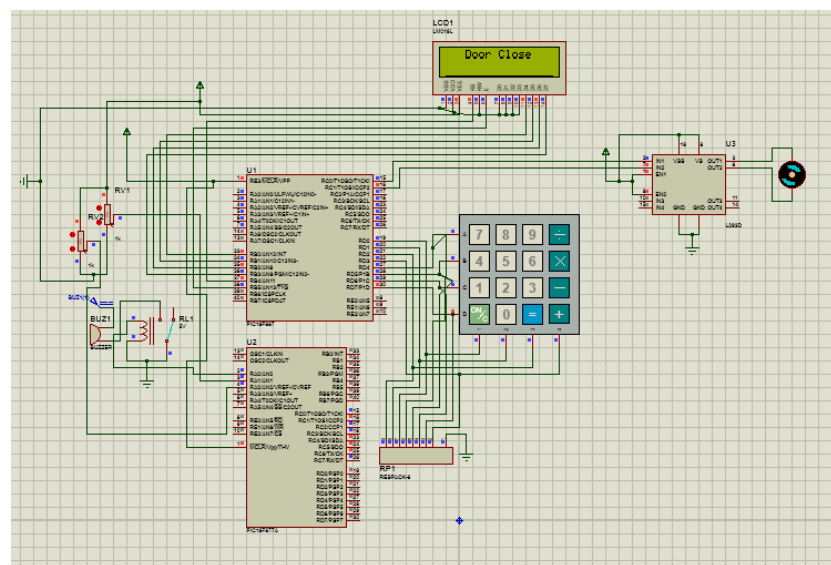

Figure 11: Shown door close on LCD after 2000 MS for door open.

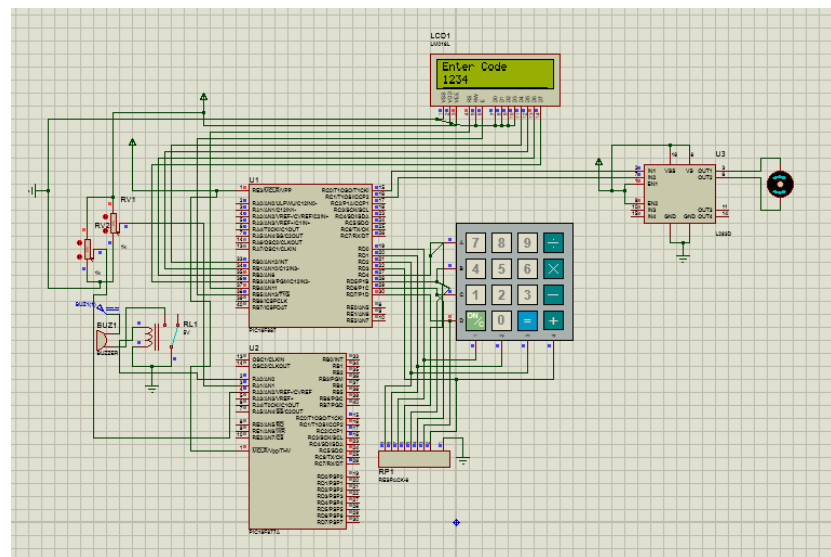

Figure 12: Shown enter the random password on LCD.

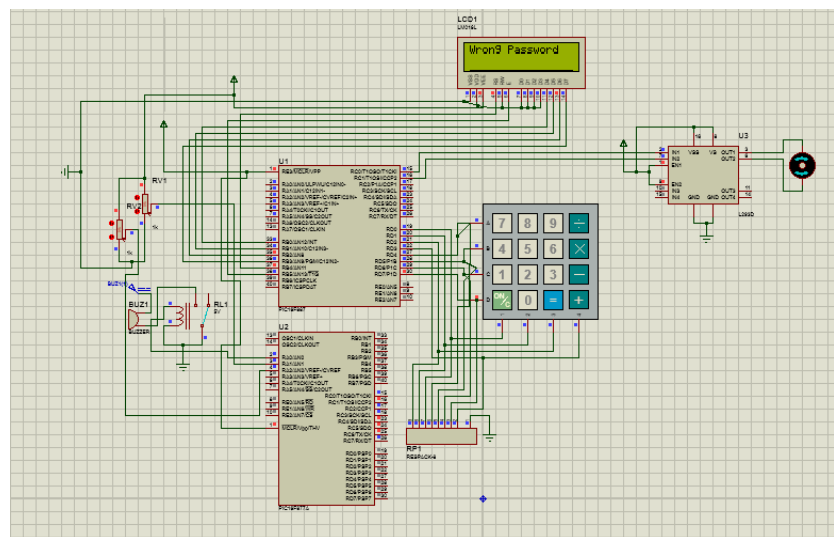

Figure 13: Shown the wrong password on LCD.

\section{Hardware and PCB}

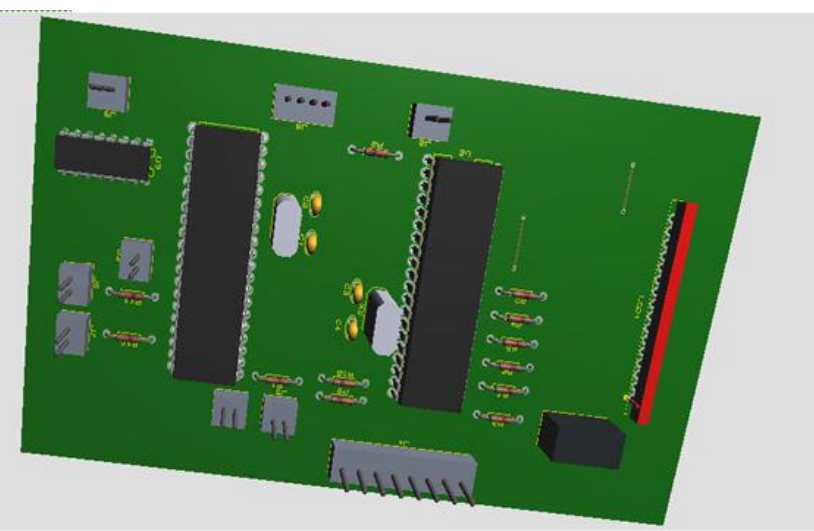

Figure 14: Shown PCB for up view.

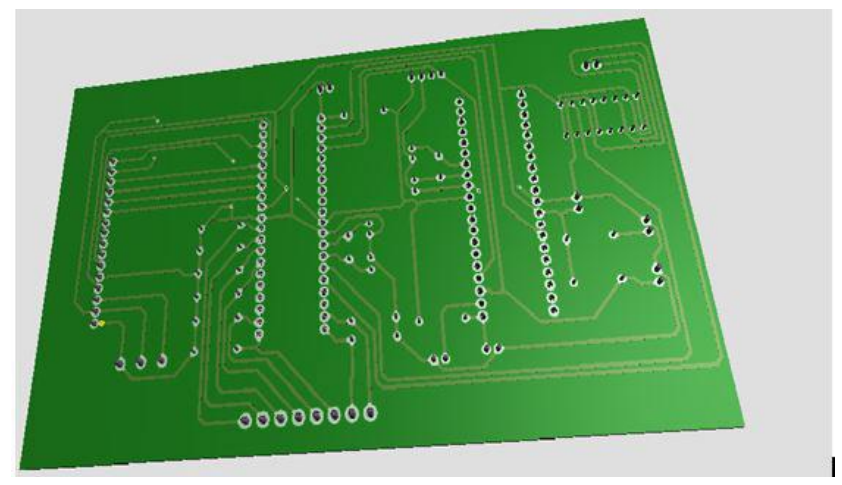

Figure 15: Shown PCB for down view.

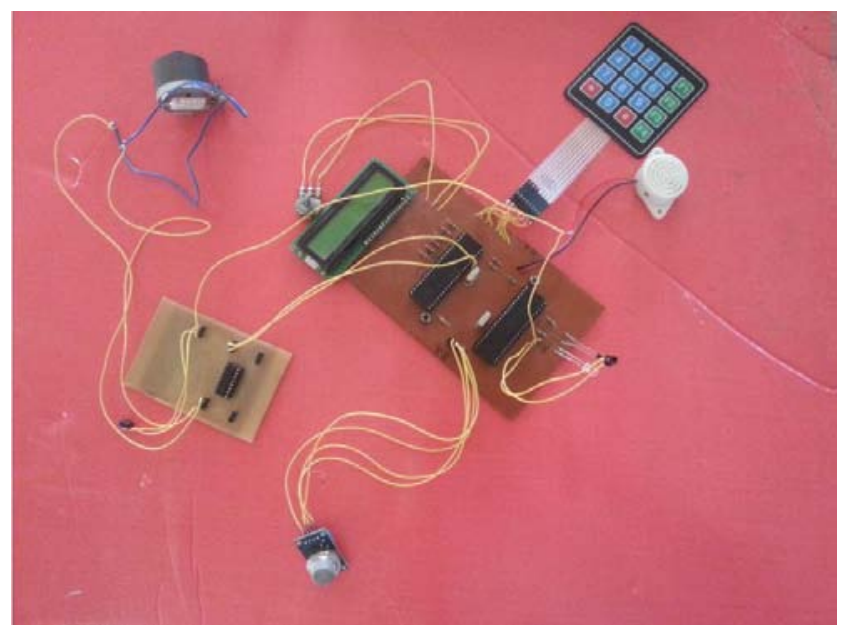

Figure 16: Shown Hardware for up view.

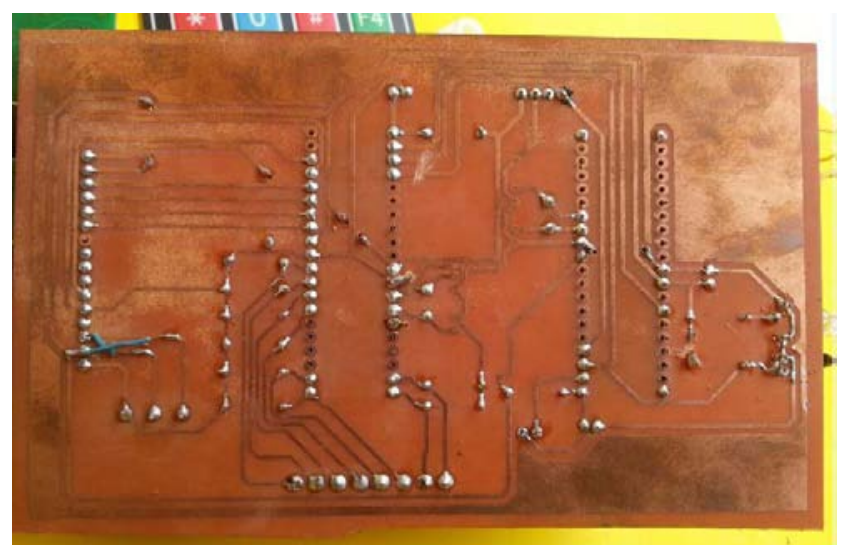

Figure 17: Shown Hardware for down view.

\section{Volume 5 Issue 3, March 2016}




\subsection{Conclusion}

The project was implemented in practice and had been to obtain the required results; the results of the practical implementation showed a high dependability and reliability for the microcontroller type PIC16f177A at the speed of data processing and give the output at the fastest time.

Security and home protection system is very importance and it must be used in any home and factory or a place with people that are available with this system to preserve the property and life in a safe environment.

\subsection{Recommendations}

Using the internet to send the data about who try to open the door by entering the wrong password. Using the internet to send the data to a microcontroller to open or close a doors/windows.

\section{Other recommendations}

Implement this project and adding fire sensors.

\section{References}

[1] www.projectsof8051.com access date: 29/12/2015. Access time 9:00 pm.

[2] Ramesh Bhardwaj, DEVELOPMENT OF HIGHASSURANCE DISTRIBUTED SYSTEMS, 2nd international workshop on requirements engineering for high assurance systems(rhase03), September 9, 2003. Monterrey bay, California, usa.in connection with the 11th IEEE international requirements engineering conference.

[3] Mitra-Thakur, Enhanced Password Based Security System Based on User Behavior using Neural Networks, I.J. Information Engineering and Electronic Business, 2012, 2, 29-35, Published Online April 2012 in MECS ( http://www.mecs-press.org),DOI: 10.5815/ijieeb.2012.02.05.

\section{Author Profile}

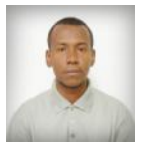

Mohamed Hassan is an electrical engineering in ZAYAWA company group. Mohamed holds a B.Sc. in control system from Alneelain University faculty of engineering Khartoum, Sudan. And post Graduates student MSC in Control System Engineering at Alneelain University, College of Graduates Studies, in Sudan.

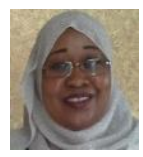

Dalia Mahmoud assistant professor and currently Head of Control Systems Department, at Alneelain University, Faculty of engineering Khartoum, Sudan. Dalia holds a Ph.D. degree and she has more than10 years ${ }^{c e}$ Experience in higher Education filed. 